\title{
The Murine P84 Neural Adhesion Molecule Is SHPS-1, a Member of the Phosphatase-Binding Protein Family
}

\author{
S. Comu, ${ }^{1}$ W. Weng, ${ }^{1}$ S. Olinsky, ${ }^{1}$ P. Ishwad, ${ }^{1}$ Z. Mi, ${ }^{2}$ J. Hempel, ${ }^{3}$ S. Watkins, ${ }^{4}$ C. F. Lagenaur, ${ }^{2}$ and \\ V. Narayanan $1,2,5$ \\ ${ }^{1}$ Department of Pediatrics, The Children's Hospital of Pittsburgh, ${ }^{2}$ Departments of Neurobiology, ${ }^{3 B}$ Biological Sciences, \\ ${ }^{4}$ Cell Biology and Physiology, and 5Neurology, University of Pittsburgh, Pittsburgh, Pennsylvania
}

P84 is a neuronal membrane glycoprotein that promotes the attachment and neurite outgrowth of cultured murine cerebellar cells. The heterophilic adhesive properties of P84 and its localization at sites of synaptogenesis suggest that it may be involved in regulation of synapse formation or maintenance. P84 is expressed in subsets of neurons throughout the CNS. By cloning the cDNA encoding murine P84, we have discovered that this molecule is a member of a family of phosphatase- binding proteins and is identical to the murine SHPS- 1 cDNA. Here we report the cloning of two alternatively spliced forms of P84 and describe its localization within the CNS by in situ hybridization.

Key words: P84; neural adhesion molecule; neurite growth; protein tyrosine phosphatase; synaptogenesis; phosphatase binding protein; SHPS-1
Two important processes during development of the CNS are the growth of axons along specific pathways and the formation of synaptic contacts with appropriate targets. Molecules that are known to guide developing axons include cell-cell or cell-substrate adhesion molecules, as well as repulsive molecules (Culotti and Kolodkin, 1996; Goodman, 1996). Much less is known about the adhesive interactions that determine target selection, termination of growth, and synaptogenesis (Fields and Itoh, 1996), although a role for cadherins in the formation of synaptic junctions in the CNS has been proposed recently (Fannon and Colman, 1996). In this report, we describe the molecular characterization of P84, a neural adhesion molecule that may have a role in synapse formation.

P84 was originally detected as a membrane protein recognized by a monoclonal antibody raised against mouse brain membrane fractions (Chuang and Lagenaur, 1990). Immobilized P84 antigen was shown to promote the adhesion of neurons and glial cells to the antigen-coated substrate as well as to promote the growth of neurites (Chuang and Lagenaur, 1990). The fact that cultured cerebellar neurons did not express P84 until after $4 \mathrm{~d}$ in vitro and the observation that glial cells that did not express P84 could adhere to the P84 substrate suggested that P84 had a heterophilic binding mechanism. The morphology of neurites and the growth cone motility of cells grown on P84 differed from cells grown on $\mathrm{N}-\mathrm{CAM}$ (neural cell adhesion molecule) or L1, implying that each molecule promoted growth by distinct mechanisms (Abosch and Lagenaur, 1993).

\footnotetext{
Received May 19, 1997; revised Aug. 22, 1997; accepted Aug. 29, 1997.

This work was supported in part by funds from the Children's Hospital of Pittsburgh and National Institutes of Health Grant NS35361. We thank Camille Diges and Wei Zhou for technical assistance.

The murine P84 sequence has been deposited with GenBank (accession number U89694).

Correspondence should be addressed to Dr. Vinodh Narayanan, Room 7151 Rangos Building, Children's Hospital of Pittsburgh, 3705 Fifth Avenue at DeSoto Street, Pittsburgh, PA 15213.

Copyright (C) 1997 Society for Neuroscience $0270-6474 / 97 / 178702-09 \$ 05.00 / 0$
}

Prenatally, P84 was detected in the floor plate region of the embryonic spinal cord as early as embryonic day 9 (E9) but was not detectable in the rest of the embryonic nervous system. Postnatally, P84 was expressed widely in the CNS, primarily in regions rich in neuropil, appearing in most areas after the second postnatal day (Chuang and Lagenaur, 1990). P84 staining was not observed in the peripheral nerves or in non-neural tissues.

In this paper, we describe the cloning and characterization of the murine P84 adhesion molecule. We have discovered that P84 is identical to SHPS-1 and homologous to signal-regulatory protein $\alpha 1$ (SIRP- $\alpha 1$ ), both being membrane glycoproteins identified as proteins that bind to tyrosine phosphatases SHP-2 and SHP-1 (Fujioka et al., 1996; Kharitonenkov et al., 1997). These observations suggest that P84 may serve to bind and modulate the activity of tyrosine phosphatases and may play a key role in intracellular signaling during synaptogenesis and in synaptic function. The combined heterophilic adhesion properties and synaptic localization of P84, as well as its potential involvement in cell signaling, suggest intriguing possible roles for P84 in regulation of synaptic stability or function. We expect that these studies will add to the growing body of knowledge dealing with the signal transduction pathways that are involved in growth-cone target interactions and synapse formation.

\section{MATERIALS AND METHODS}

Peptide fragment preparation and sequencing. P84 antigen was purified by immunoaffinity chromatography as described previously (Chuang and Lagenaur, 1990), and the 77 and $86 \mathrm{kDa}$ bands were isolated from $8 \%$ SDS-PAGE gels as described by Mendel-Hartwig (1982). Both purified bands were reduced, alkylated, and subjected to N-terminal sequence analysis. The $86 \mathrm{kDa}$ band was also treated with trypsin, and peptides were isolated on a microbore $\mathrm{C} 18$ column (Vydac). One internal peptide was selected for sequence analysis.

Oligonucleotide primer design. Custom oligonucleotides were synthesized (Genosys Inc.). R represents A or G; Y represents T or C; and I represents inosine, which pairs with any base. The N-terminal peptide sequence was KELKVTQPEKSVSVAAGDSTVL, and the upper primer corresponded to the first six amino acids (P84.U1, 5'-AAR GAR 
YTI AAR GTI ACI CA). The sequence of the internal tryptic peptide was ITQIQDTN, and the lower antisense primer corresponded to the last seven amino acids (P84.L1, 5'-TT IGT RTC YTG IAT YTG IGT-3').

cDNA cloning and sequencing. Starting with total RNA extracted from postnatal day 15 (P15) mouse cerebella, we prepared cDNA with the P84.L1 degenerate primer and then amplified it with P84.U1 and P84.L1. Amplified fragments were gel purified, cloned into pBluescript (Stratagene, La Jolla, CA), and sequenced. These fragments were also used to screen a neonatal mouse brain cDNA library constructed in UniZAP (Stratagene). Gene specific primers were synthesized for $3^{\prime}$ - and $5^{\prime}$-end amplification and further sequencing. The $3^{\prime}$ end was obtained by PCR amplification using Marathon Ready cDNA pools from mouse brain (Clontech, Cambridge, UK). The $5^{\prime}$ end was isolated by a modified single-strand ligation to ss-cDNA method (Dumas et al., 1991). Starting with mouse cerebellar RNA, first-strand cDNA was synthesized with a P84-specific primer (5'-CCC ACA CCG ATG AAG ACA-3'), followed by alkaline hydrolysis of the RNA and purification of the cDNA. An anchor primer $\left(5^{\prime}\right.$-phosphate CTA TAG TGT CAC CTA AAT CGT ATG TGT ATG ATA C-3', C6 amino modifier) was ligated to the single-stranded cDNA using T4 RNA ligase (New England Biolabs, Beverly, MA) in a buffer containing $1 \mathrm{~mm}$ hexammonium cobalt chloride, 20 uM ATP, and 25\% polyethylene glycol 8000 (Apte and Siebert, 1993). An aliquot of this anchor-ligated cDNA was used in a PCR reaction with an adapter primer (SP-6, 5'-CAT ACG ATT TAG GTG ACA CTA TAG-3') complementary to part of the anchor primer and with a P84specific primer (5'-GGA GTT CTT GCC CAT CTT TG-3'). This was reamplified with SP-6 and a nested primer $\left(5^{\prime}-\mathrm{CCT}\right.$ ACT CCT CTG TAC CAC TTA ATG-3'). PCR fragments were gel-purified and cloned into pT7-Blue vector (Novagen, Madison, WI). Both strands of the full-length cDNA were sequenced using a panel of internal primers.

$R N A$ analysis. Northern blots were prepared by electrophoresis of total RNA through formaldehyde-agarose gels and transferred to nylon membranes via use of standard protocols. Blots were stained with methylene blue to verify even intensity of ribosomal RNA bands (Herrin and Schmidt, 1988). Blots were hybridized with the SC500 cDNA probe.

For reverse transcriptase (RT)-PCR studies of the relative abundance of the different P84 isoforms, total RNA was extracted from various murine tissues, and cDNA was synthesized using the L2800 primer (5'-CCA GAT AGT CAG GGT TGC-3'). These cDNA pools were used as templates for PCR amplification using primers U36 (5'-GTC TGT TGC TGC TGG GGA TTC-3') and L647 (5'-CCC ACA CCG ATG AAG ACA $\left.-3^{\prime}\right)$. These primers were designed to yield an $\sim 1 \mathrm{kbp}$ band for the large P84 mRNA and a $340 \mathrm{bp}$ band for the small P84 mRNA. The full-length P84 cDNA and the SC500 cDNA were used as positive controls.

In situ hybridization. A Bam $\mathrm{HI}-X b a \mathrm{I}$ fragment of the $3^{\prime}$-untranslated region of the P84 cDNA (see Fig. $1 A$ ) was cloned into pBluescript (Stratagene). Digoxigenin-labeled sense and antisense riboprobes were synthesized by in vitro transcription with either T7 or T3 RNA polymerase. Cryostat sections $(16 \mu \mathrm{m})$ were cut from P15 mouse brains. Hybridization of digoxigenin-labeled RNA probes with tissue sections essentially followed the protocol of Schaeren-Wiemers and Gerfin-Moser (1993). In each experiment, control slides were hybridized with sense RNA probes, washed, and stained for the same time as antisense probed slides. There was minimal background staining with the sense probe.

Deglycosylation. Affinity-purified P84 containing 86 and 77 kDa bands was resolved with SDS-PAGE, and the bands were eluted from Commassie blue G-stained gels. The purified proteins were boiled in PBS containing 1\% 3-[(3-cholamidopropyl)dimethylammonio]-1-propane sulfonate. The samples were adjusted to $10 \mathrm{~mm}$ EDTA, and $4 \mathrm{U} / \mathrm{ml} \mathrm{N}$ glycocidase F (Boehringer Mannheim, Indianapolis, IN) was added. Digestion was performed for $4-7 \mathrm{hr}$ at $37^{\circ} \mathrm{C}$ and analyzed by SDS-PAGE.

Immunohistochemistry. Animals were perfused with $0.06 \%$ glutaraldehyde and $2 \%$ paraformaldehyde in PBS, cryoprotected with $2.3 \mathrm{M} \mathrm{su}-$ crose, and sectioned at $0.2 \mu \mathrm{m}$ (Singer et al., 1982). Sections were cut at liquid nitrogen temperature using a Leitz Ultracryomicrotome. Tissue sections were collected on pretreated slides (Fisher Scientific, Houston, $\mathrm{TX}$ ) and stained with primary antibodies for $1 \mathrm{hr}$, washed, and incubated with fluorescence-conjugated secondary antibodies for $1 \mathrm{hr}$.

\section{RESULTS}

\section{Full-length P84 cDNA cloning}

The N-terminal amino acid sequences of the 77 and $86 \mathrm{kDa}$ forms of purified P84 were determined, yielding the first 20 residues of the $86 \mathrm{kDa}$ form (KELKVTQPEKSVSVAAGDSTVL) and the first 10 residues of the $77 \mathrm{kDa}$ form (which were identical to the residues of the $86 \mathrm{kDa}$ sequence). Purified P84 was subjected to digestion with trypsin, and the amino acid sequences of selected fragments were determined. The sequence of one of the selected internal tryptic fragments was ITQIQDTN. We designed degenerate, inosine-containing primers based on these two peptide sequences and used them to amplify the corresponding cDNA. Starting with P15 mouse cerebellar polyA RNA and using P84.L1 to prime first-strand cDNA synthesis and the combination of P84.U1 with P84.L1 for PCR amplification, we detected several cDNA fragments. The two most prominent (500 and $1200 \mathrm{bp}$ long) were cloned and sequenced (clones SC500 and SC1200, respectively). The $1200 \mathrm{bp}$ cDNA fragment contained an insertion of $\sim 700$ bp at position 460 , indicating that these two species were derived by alternative splicing from a single gene. Comparison of the translated SC500 and SC1200 amino acid sequences with the known P84 N-terminal sequence and the internal peptide fragment sequence confirmed that these two did represent P84. The SC500 cDNA fragment was then used to screen a mouse brain cDNA library, and a single positive clone (VN19.11) was purified and sequenced. Additional oligonucleotide primers were synthesized that were used to amplify the $3^{\prime}$ and the $5^{\prime}$ ends of the cDNA. Pieced together, these encode a 3605 bp cDNA (not including the polyA tail).

The two forms of P84 mRNA (large and small) are diagrammed in Figure $1 A$. The smaller form of P84 mRNA lacks the segment from base pair 461 through 1114, a result of alternative splicing of exons. By analysis of mouse genomic clones, we have confirmed that the segment between base pair 461 and 1114 corresponds to a single exon flanked by consensus splice acceptor and donor sites (data not shown). An open reading frame extends from position 23 to 1549 , encoding a 509-amino-acid peptide, the translated amino acid sequence of which is shown in Figure $1 B$. The expected molecular weight of this peptide is $56 \mathrm{kDa}$, with a pI of 8.79 . The segment that is removed by splicing to generate P84 small (accounting for 218 amino acids) is shown. At the $\mathrm{N}$ terminal, there is a hydrophobic segment that most likely represents the signal peptide, with a consensus site for signal peptidase at residue 31. Amino acid residue 32, which immediately follows this signal sequence, marks the beginning of the $\mathrm{N}$ terminal of purified P84 that was subject to peptide sequencing. A second hydrophobic segment, which most likely corresponds to a transmembrane domain, lies between residues 374 and 396. The cytoplasmic segment contains at least one potential phosphorylation site on a Thr residue (REIT at residue 423 ) and four potential Tyr phosphorylation sites $(436,460,477$, and 501). The extracellular domain contains 17 potential $\mathrm{N}$-glycosylation sites (NXS or NXT), suggesting that the discrepancy between the calculated molecular weight of the peptide and the apparent molecular weight on SDS-PAGE is because of glycosylation. Of these, only four are present in the P84 small peptide. To determine the contribution of $\mathrm{N}$-linked carbohydrate to the apparent molecular weight of P84, we digested the 86 and 77 kDa bands with $N$-glycosidase F. As shown in Figure 2, molecular weight shifts from 86 to 64 and from 77 to $42-55 \mathrm{kDa}$ were observed.

\section{Sequence homologies}

Segments of the P84 peptide sequence were used in a BLAST search of the GenBank protein database (Altschul et al., 1990). 
(A)

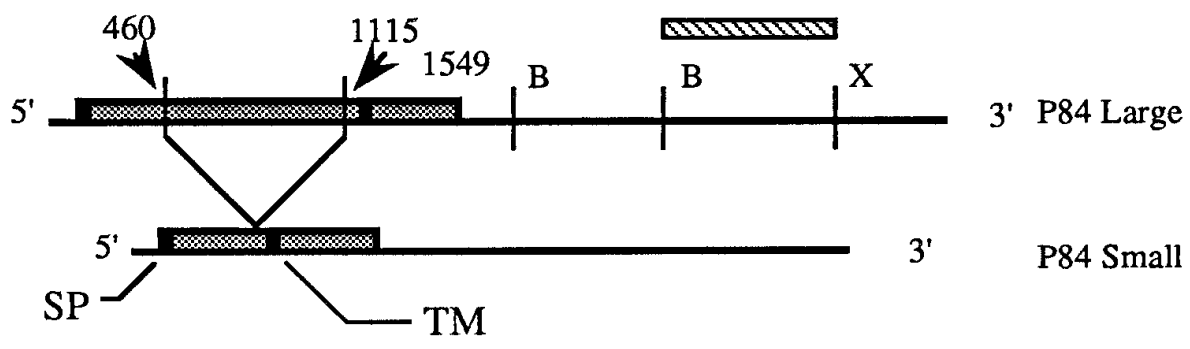

(B)

MEPAGPAPGL LGPLLLCLLL SASCFCTGAT G KELKVTQPE KSVSVAAGDS

TVLNCTLTSL LPVGPIKWYR GVGQSRLLIY SFTGEHFPRV RNVSDTTKRN

NMDFSIRISN VTPEDAGTYY CVKFQRGSSE PDTEIQSGGG TEVYVL AKPS

PPEVSGPADR GIPDQKVNFT CKSHGFSPRN ITLKWFKDGQ ELHHLETTVNㅡㄴ

PSGKNVSYNII SSTVRVVLNS MDVHSKVICE VAHITLDRSP LRGIANLSNF

KNLLTKNTDGT YNYTSLFLVN SSAHREDVVF TCQVKHDQQP AITRNHTVLG

\section{YASVQVQRK}

Figure 1. A, Diagram of large and small forms of P84 cDNA. The exon corresponding to bases 461-1114 is removed by alternative splicing to generate the P84 small mRNA. The protein coding region is shown as a shaded box, whereas the signal peptide $(S P)$ and transmembrane domain $(T M)$ are indicated as black boxes. The positions of Bam HI $(B)$ and $X b a \mathrm{I}(X)$ sites within the $3^{\prime}$-untranslated region are shown. The segment of the cDNA that was used to prepare RNA probes for in situ hybridization is shown as a hatched box over the corresponding Bam HI and $X b a \mathrm{I}$ sites. $B$, The translated peptide sequence corresponding to P84 large mRNA. The peptide segment that is removed by splicing (shown in $A$ ) is located between the arrowheads. Four potential Tyr phosphorylation sites and one possible Thr phosphorylation site in the cytoplasmic domain are shown by shadowing. Potential $\mathrm{N}$-glycosylation sites in the extracellular domain are shown as bold and underlined characters. The signal peptide and the single transmembrane domain are indicated by underlining, whereas two Pro-rich segments are indicated by heavy underlining. The N-terminal peptide fragment and the internal tryptic peptide fragment that were sequenced are boxed.

We found that homologs of P84 have been isolated from rat and human tissues (Fujioka et al., 1996; Kharitonenkov et al., 1997). These molecules, SHPS- 1 and SIRP- $\alpha 1$, were discovered based on their ability to bind to a cytoplasmic tyrosine phosphatase that contained SH2 domains (SHP-2). The murine SHPS-1 sequence has also been recently published and is identical to the P84 sequence but includes an additional $390 \mathrm{bp}$ of the $5^{\prime}$-untranslated region (Yamao et al., 1997).
The extracellular part ( $\mathrm{N}$ terminal) of P84 contains three Ig-like loops formed by Cys-Cys disulfide bridges. The smaller form of P84 (derived by alternative splicing) includes only the first Ig loop. The outer Ig loop is similar to the variable $(\mathrm{V})$ region of $\kappa$-light chains, whereas the second is similar to the constant (C) segment of Ig- $\lambda$, and the third loop is similar to the CH1 segment of $\gamma$-heavy chains (Fig. $3 A-C$ ). The cytoplasmic domain of P84 has several short regions that are similar to the insulin receptor 


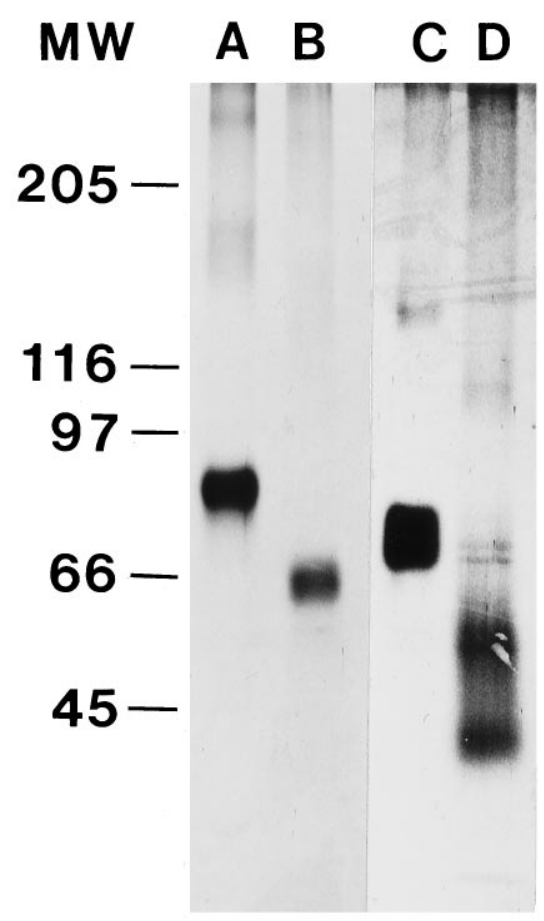

Figure 2. Deglycosylation of P84. Lanes $A, C$, The 86 and $77 \mathrm{kDa}$ bands purified by affinity chromatography and electrophoresis. Lanes $B, D$, The same peptides treated with $N$-glycosidase F. Apparent shifts in molecular weight from 86 to 64 and from 77 to $42-55 \mathrm{kDa}$ are observed. Molecular weights in kilodaltons are indicated on the left.

substrate-1 (IRS-1) (Fig. 3D), a molecule that is phosphorylated on Tyr residues on exposure of cells to insulin or other growth factors (Sun et al., 1991). These regions are near phosphorylation sites (either Thr or Tyr) and a Pro-rich region. In addition, the transmembrane and juxtamembrane segments of P84 have considerable similarity to receptor protein tyrosine phosphatase $\alpha$ (Fig. 3E).

The human homolog of P84 (accession number HSU06701) was first isolated from a human brain cDNA library in a search for sequences that contained triplet repeats (Margolis et al., 1995). This particular sequence contained a short CCA repeat, with either 10 or 11 repeats in the various individuals that were studied. Whether expansion of this triplet repeat occurs in human disease remains to be seen. HSU06701 was shown to be on chromosome 20 using human-rodent somatic cell hybrids. We have recently mapped the human P84 gene to the subtelomeric region of chromosome 20, close to the polymorphic marker D20S199 (Eckert et al., 1997; Yamao et al., 1997). There is a high degree (90-95\%) of similarity between murine, rat, and human SHPS-1 (P84) amino acid sequences (Yamao et al., 1997).

\section{P84 mRNA distribution by Northern analysis, RT-PCR, and in situ hybridization}

The P84 cDNA probe hybridized to an mRNA species that is $\sim 4$ $\mathrm{kb}$ and is present in the cerebral cortex and cerebellum (Fig. 4, left). In addition to the prominent band at $4 \mathrm{~kb}$, there were lighter bands visible that corresponded to smaller mRNAs. Whether these represented cross-hybridization to other mRNA species or smaller spliced forms of P84 remains to be determined. The P84 mRNA was also detected in the spinal cord and, at much lower levels, in kidney, heart, and liver (Fig. 4, right).
We have examined the question of relative abundance of the different P84 mRNA species in a variety of tissues by Northern blot analysis and by RT-PCR. A 26 bp oligonucleotide, P84.small.L333 (5'-TAG CAT TAT TAC CGA GTA CAT AGA CC-3'), complementary to $13 \mathrm{bp}$ on either side of the splice site at position 460 in the smaller form of the P84 mRNA, was used as a probe for Northern blot analysis. Stringency of the washing condition $\left[64^{\circ} \mathrm{C}\right.$ in a methyl ammonium chloride wash (Wood et al., 1985)] was such that partial hybridization of this probe with the larger form of P84 mRNA would not be detected. A very faint signal was detected in all tissues tested (data not shown), suggesting that the major form of P84 mRNA was the large form. An RT-PCR study was also performed with primers U36 and L647, designed to amplify $\sim 1 \mathrm{kbp}$ and $340 \mathrm{bp}$ bands from the large and small P84 mRNAs, respectively. As shown in Figure 5, both mRNA species are detected by RT-PCR in cerebellum, cerebral cortex, spinal cord, and other tissues, but the intensities of the bands on this gel may not reflect the relative abundance of these two species because of the high cycle number used in the amplification program. When reverse transcriptase is omitted in the cDNA synthesis step, no PCR bands are amplified, supporting the idea that these correspond to mRNAs and not genomic DNA. An intermediate-sized band also appears in this PCR result, suggesting that there may be other alternatively spliced forms of this mRNA.

Earlier studies had identified the cerebellum as a site of high P84 expression. To better examine the distribution of P84 antigen in the cerebellum, we prepared ultracryomicrotome sections and stained them for P84. As shown in Figure 6, P84 staining was intense throughout the molecular layer. Within the granule cell layer, P84 staining was weak on granule cell bodies, but intense staining was observed on small ring-shaped structures the dimensions $(2-4 \mu \mathrm{m})$ and distribution of which correspond to that of synaptic glomeruli (Palay and Chan-Palay, 1974). We have compared this antibody-staining pattern to the distribution of P84 mRNA within the mouse brain by in situ hybridization. There was a prominent hybridization signal in the cerebellar granule cell layer, along with a monolayer of cells just below the Purkinje cell layer (Fig. 7). These do not represent Purkinje cells (which have large perikarya) but most likely correspond to Golgi epithelial cells. The deep cerebellar nuclei do not seem to express this mRNA. The neurons in the hippocampus and the dentate gyrus also expressed P84, although a conspicuous region of low expression is consistently observed at the CA1-CA3 border (Fig. 8). There was a variation in the level of expression of P84 in different cortical layers of the cortex resulting in a laminar pattern with the most prominent expression in layer IV. Figure 8 also demonstrates expression of P84 mRNA in the olfactory bulb, particularly in the mitral and periglomerular neurons. Thus P84 was expressed in many, but not all, classes of neurons in the brain. The Purkinje cells and the deep nuclei of the cerebellum did not express this gene.

\section{DISCUSSION}

P84 antigen was originally identified as a neural membrane protein that was capable of supporting neurite outgrowth from cultured cerebellar or neocortical cells (Chuang and Lagenaur, 1990; Abosch and Lagenaur, 1993). In the present study we have shown that P84 is identical to SHPS-1 (Yamao et al., 1997) and homologous to the family of SIRP- $\alpha$ and $\beta$ gene products described by Kharitonenkov et al. (1997). Our findings, coupled with those of these other groups, suggest that P84 and related family members 
(A)

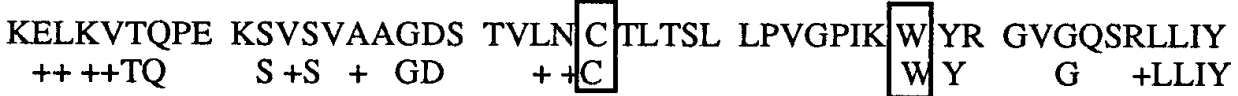

$$
\begin{aligned}
& \text { SFTGEHFPRV RNVSDTTKRN NMDFS I RISN VTPEDAGTYY C VKFQRGSSE } \\
& +\mathrm{G} \mathrm{H} \quad \mathrm{D}+\mathrm{S}+\mathrm{ISN}+\mathrm{PED} \text { TYY }+++
\end{aligned}
$$

(B)

$$
\begin{aligned}
& \text { GGG TEVYVL AKPS PPEVSGPADR GIPDQKVNFT C KSHGFSPRN ITLK WKDGQ } \\
& \text { GGG } \mathrm{T}+\mathrm{V} \quad \mathrm{VL}+\mathrm{P} \quad \mathrm{P}+++\mathrm{K} \quad \text { C] } \mathrm{FSP}+\mathrm{T}+\mathrm{W}+\mathrm{G} \\
& \text { ELHHLETTVN PSGKNVSYNI SSTVRVVLNS MDVHSKVICE VAHITLDRSP } \\
& +\quad \mathrm{T} \mathrm{N} \mathrm{P+}++\mathrm{SS}+++\mathrm{H}+\mathrm{C}+\mathrm{VH}
\end{aligned}
$$

$$
\begin{gathered}
\text { VSPTVKVT QQSPTSMNQV NLT } \\
\mathrm{Q}+\mathrm{NQV}+\mathrm{CT} \\
\mathrm{C}
\end{gathered} \begin{array}{r}
\text { RERFY PEDLQLI } \\
+\mathrm{FY}
\end{array}
$$

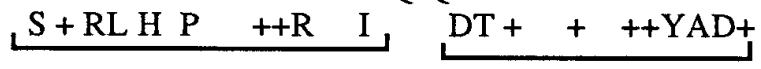
with conservative substitutions indicated by + . Conserved Cys $(C)$ and $\operatorname{Trp}(W)$ residues are boxed. $D$, Alignment of the cytoplasmic domain with segments of the mouse and human IRS-1 peptide. The segments of mouse IRS-1 are not contiguous and are similar to regions of P84 around Thr and Tyr phosphorylation sites. Also shown here is the similarity to a short Pro-rich segment of human IRS- 1 . E, Alignment of the transmembrane and juxtamembrane segments of P84 with receptor protein tyrosine phosphatase $\alpha$.

represent a group of proteins that potentially interact with nonreceptor tyrosine phosphatases via their cytoplasmic domains and with cellular receptors via their extracellular domains. It is not clear whether the binding of extracellular ligands influences the binding properties or functionality of the cytoplasmic domains.

P84 is encoded by an $\sim 4 \mathrm{~kb}$ mRNA and expressed at high levels in the CNS and at much lower levels in other tissues (heart, liver, kidney, spleen, and thymus). Within the brain, the cerebellum, hippocampus, and olfactory bulb are regions of intense expression. We have identified two forms of P84 derived by alternative splicing. Others have found a third splicing variant, generated by an alternative splice acceptor site (Yamao et al., 1997). Fujioka et al. (1996) have been able to detect the expression of rat SHPS-1 mRNA as a single $4.2 \mathrm{~kb}$ species in brain, lung, and spleen and at lower levels in other tissues. Similar Northern blot analysis in human tissues with a SIRP- $\alpha$ probe (Kharitonenkov et al., 1997) showed hybridization to two major transcripts of 3.9 and $2.5 \mathrm{~kb}$ in all tissues and several weaker bands. The identities of these other mRNA species is not yet known. Our Northern blot data suggest that the major species of P84 mRNA corresponds to the $4 \mathrm{~kb}$ mRNA. The small form of P84 mRNA (derived by alternative splicing) and an intermediate form can be detected by RT-PCR. Whether stable proteins corresponding to these other forms of P84 mRNA exist and what their function may be are not known. Immunoaffinity purification of P84 from brain identifies two distinct polypeptides; these may represent translation products of distinct alternatively spliced mRNA species. It is important to recognize that multiple forms of P84 mRNA (and perhaps protein) exist. This may represent a strategy to generate many forms of this adhesion/recognition molecule with varying binding specificity to its extracellular binding partner. 


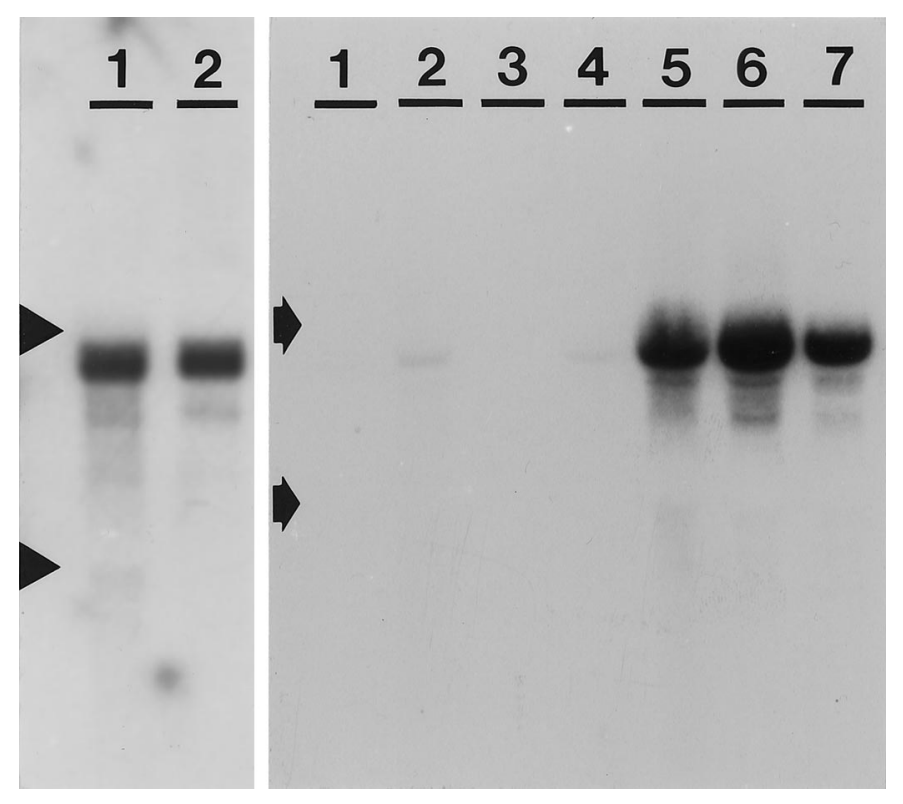

Figure 4. Left, Northern blot of cerebellum (lane 1) and cerebrum (lane 2) from P15 mouse probed with P84 cDNA demonstrates a thick band just below the 28S rRNA marker (corresponding to $\sim 4 \mathrm{~kb}$ ). The blot was prepared by electrophoresis of $10 \mu \mathrm{g}$ of total RNA per lane. Right, P84 expression in neural and non-neural tissues. Northern blot prepared with RNA (10 ug per lane) from liver (lane 1), kidney (lane 2), skeletal muscle (lane 3), heart (lane 4), spinal cord (lane 5), cerebrum (lane 6), and cerebellum (lane 7). This represents an overexposed autoradiogram, showing faint bands in liver, kidney, and heart. Arrowheads and arrows correspond to 28 and $18 \mathrm{~S}$ rRNA bands.

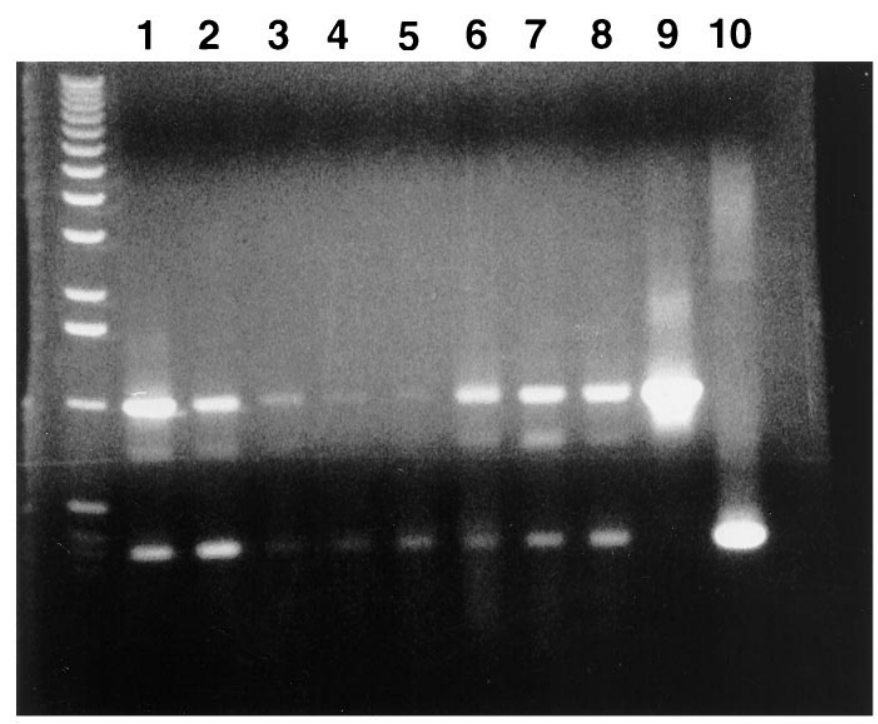

Figure 5. Detection of large and small forms of P84 mRNA in different tissues by RT-PCR. cDNA pools from cerebellum (lane 1), cerebral cortex (lane 2), spleen (lane 3), thymus (lane 4), liver (lane 5), skeletal muscle (lane 6 ), heart (lane 7), and spinal cord (lane 8) were amplified with the U36 and L647 primers. Lane 9 is a positive control reaction done with the full-length (large) P84 cDNA as template, and lane 10 is a positive control using SC500 plasmid DNA (partial small cDNA) as template. To the left of lane 1 is a 1 $\mathrm{kb}$ ladder.

The P84 adhesion molecule contains a single transmembrane domain. The large form of P84 contains three Ig-like loops in its extracellular domain, whereas the small form of P84 contains only one Ig-like loop. The outermost Ig-loop (which is shared by both
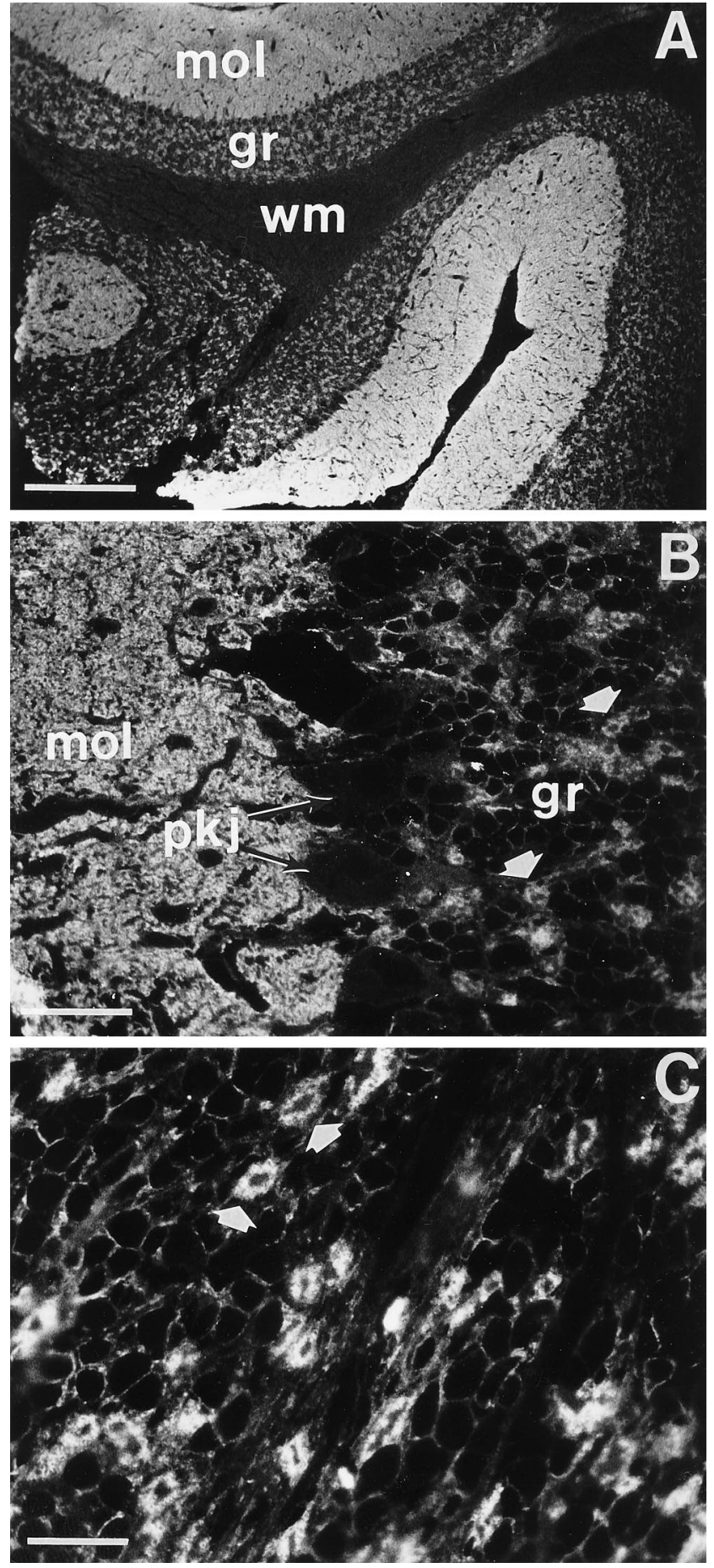

Figure 6. Immunohistochemical localization of P84 in cerebellum. U1tracryomicrotome sections showing intense P84 staining in the molecular layer $(A-C)$ and in synaptic glomeruli (ring-shaped structures indicated by arrows in $B$ and $C$ ). Weak staining is observed on granule cell bodies. pkj, Purkinje cells; other abbreviations are defined in the Figure 7 legend. Scale bars: $A, 200 \mu \mathrm{m} ; B, 50 \mu \mathrm{m} ; C, 30 \mu \mathrm{m}$.

large and small forms) is similar to the $\mathrm{V}$ region of $\kappa$-chains, suggesting a role in specifically recognizing an extracellular binding partner. The extracellular domain also contains many $\mathrm{N}$ glycosylation sites, accounting for the difference between calculated peptide molecular weight and the apparent molecular 

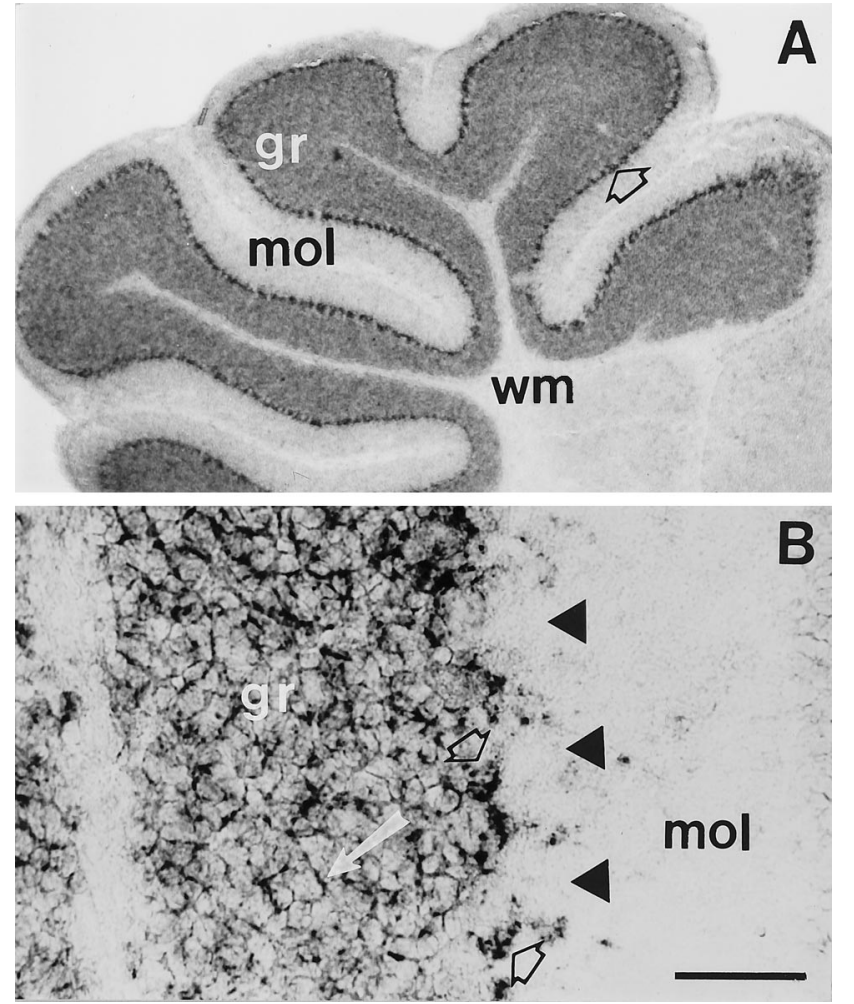

Figure 7. P84 mRNA distribution in the cerebellum. A, P84 in situ hybridization of a parasagittal section of adult cerebellum. Prominent expression is detected in the granule cell layer $(g r)$, and no signal is observed in the molecular layer $(\mathrm{mol})$ or white matter $(\mathrm{wm})$. Particularly strong expression is observed in a layer immediately below the layer of Purkinje cells. $B$, A higher magnification of the cerebellar cortex. Here, the strong signal in the thin cytoplasm of granule cells is apparent (white arrow). The Purkinje cells (black arrowheads) are unstained, whereas a strong layer of staining just below the Purkinje cells is indicated with open arrows. Scale bar: $B, 40 \mu \mathrm{m}$.

weight by SDS-PAGE. The cytoplasmic domain contains four potential Tyr phosphorylation sites, with surrounding sequences that are shared by proteins (such as IRS-1) that interact with $\mathrm{SH} 2$ domains of other proteins. There seems to be some specificity in the interaction between different $\mathrm{SH} 2$ domain-containing proteins and the target phosphotyrosine-containing peptides (Beattie, 1996).

The P84 adhesion molecule is homologous to the rat SHPS-1 protein and to the human SIRP- $\alpha 1$ protein. Both molecules were recently isolated on the basis of their binding to a cytoplasmic tyrosine phosphatase, SHP-2 (Fujioka et al., 1996; Kharitonenkov et al., 1997). The murine SHPS-1 cDNA has also been recently cloned and sequenced and is virtually identical to the P84 sequence (Yamao et al., 1997). The rat SHPS-1 protein is most prominent in brain but appears in a number of other tissues as well. It binds SHP-2 and SHP-1, both cytoplasmic tyrosine phosphatases that contain $\mathrm{SH} 2$ domains. Another murine brain membrane protein that binds SHP-2 has recently been identified. Designated BIT (brain Ig-like molecule with Tyr-based activation motifs), this 509-amino-acid Tyr-phosphorylated molecule is thought to stimulate SHP-2 activity (Ohnishi et al., 1996). The sequences of the primers used to amplify the cytoplasmic segment of BIT are identical to that of segments of P84, suggesting that BIT, P84, and SHPS-1 are identical. Recently, it has been
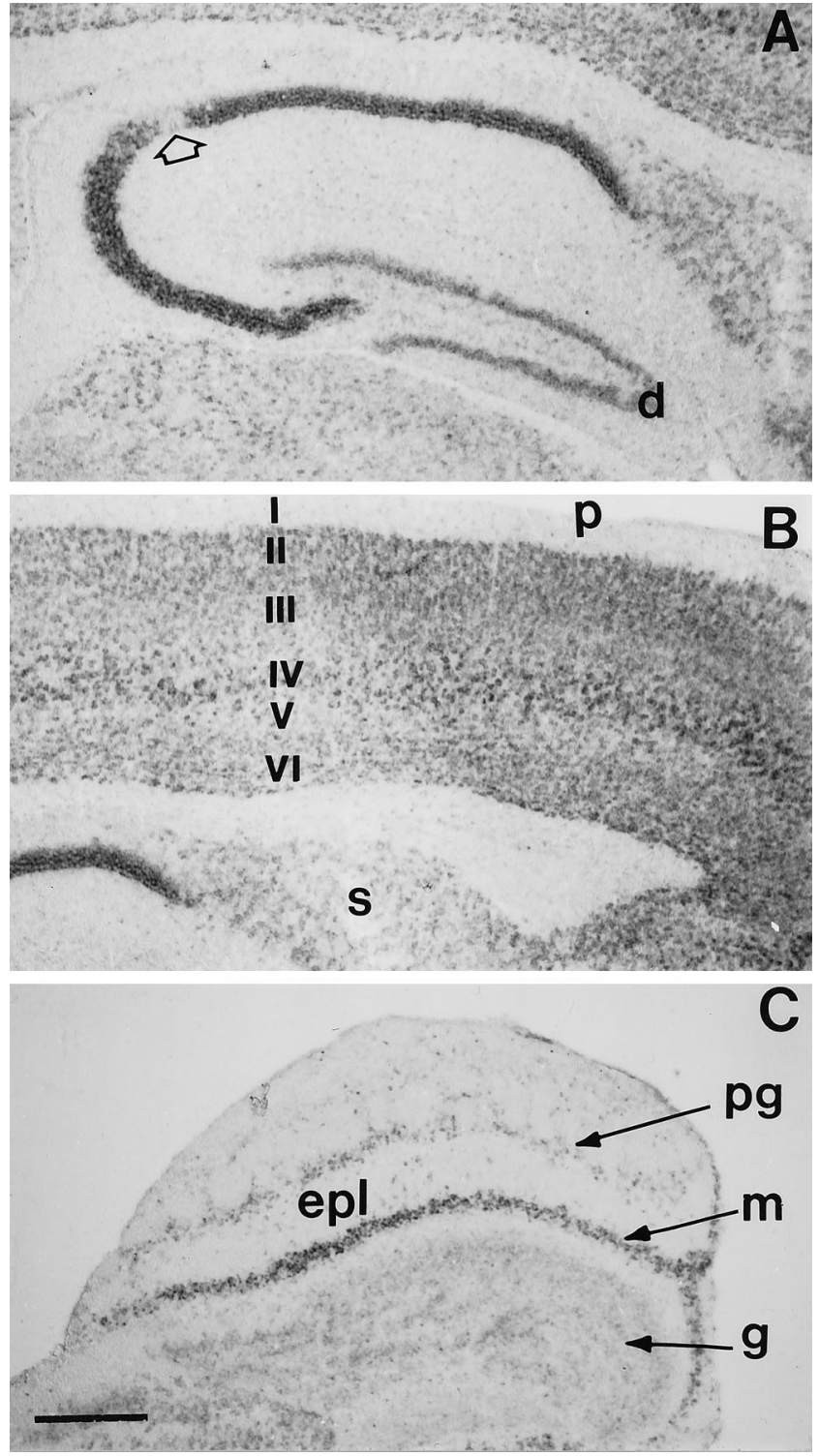

Figure 8. P84 mRNA distribution in selected brain regions. A, A parasagittal section of hippocampus. Note the prominent staining of granule cells of the dentate gyrus $(d)$ and the absence of staining at the CA1-CA3 border, indicated by the open arrow. $B$, A parasagittal section of the caudal portion of neocortex. Note the laminar variation in P84 expression with particularly strong expression in layer IV. $p$, Pia; $s$, subiculum. $C$, A parasagittal section of olfactory bulb. $m$, Mitral cell layer; $p g$, periglomerular cells; epl, external plexiform layer; and $g$, granule cells. Scale bar, $300 \mu \mathrm{m}$.

shown that SHP-2 dephosphorylates SIRP- $\alpha 1$ (the human homolog of P84) in vitro (Kharitonenkov et al., 1997). SHP-2 also seems to serve as an adapter in mediating the interaction between the insulin receptor and IRS-1 (Kharitonenkov et al., 1995). Considering the similarity between the cytoplasmic domains of P84 and IRS-1, one may speculate that SHP-2 (protein tyrosine phosphatase 1D) may serve a similar adapter function between P84 and other receptors that are in neurons.

The human homolog of P84 was first isolated as a brain cDNA that contained a short CCA repeat. This short CCA repeat (10 or 11 repeats) is located within the $3^{\prime}$-untranslated region of the gene. This gene has been mapped to the subtelomeric region of 
human chromosome 20 (close to polymorphic marker D20S199; Eckert et al., 1997). This gene lies outside the critical region for Hallervorden-Spatz syndrome, a progressive neurological disorder mapped to 20p13. We believe that genetic defects in P84 may not cause major malformations of the brain but may result in improper synapse formation and thus cause symptoms such as mental retardation and seizures. There are a number of human disorders (fragile X syndrome, myotonic dystrophy, Huntington's disease, spinocerebellar ataxia, and Friedrich's ataxia) that are caused by expansions of triplet repeats (Ashley and Warren, 1995; Timchenko and Caskey, 1996). It is thus possible that expansion of the CCA repeat in the human P84 (SHPS-1) gene may cause such a neurological syndrome.

The immunohistochemical and in situ hybridization data suggest that P84 is localized to regions of the brain that are rich in synapses. In the cerebellum, P84 mRNA is easily detected in granule cells but not in Purkinje cells, whereas the protein is localized to the molecular layer and to synaptic glomeruli within the granule layer. Because the neuronal components of the molecular layer of the cerebellum consist mainly of axons of the granule cells (parallel fibers) and Purkinje cell dendrites, these observations are consistent with a presynaptic localization of the protein. Whether this presynaptic localization applies in other regions of the brain is unknown, and it may be that in certain structures P84 may appear postsynaptically. P84 mRNA is detected throughout the brain including the hippocampus, cerebral cortex, olfactory bulb, and retina. This localization of P84 to synapses, its in vitro function as an adhesion molecule, and the structural information contained in this paper showing the similarity to $\mathrm{V}$ regions of Igs suggest that the interaction between the extracellular domain of P84 and its receptor (or ligand) may be important in synapse formation or maintenance. It is not clear whether extracellular ligand binding influences the binding or activity of SHP-2 phosphatase. Because P84 becomes localized to synaptic regions in the CNS, it is possible that its function is to effect the localization of SHP-2 to this region and thus spatially regulate SHP-2 expression.

Interesting parallels may be drawn between P84 (SHPS-1) and SHP-2 association and SHP-1 association with Tyrphosphorylated proteins in hematopoietic cells. Natural killer (NK) cells express a class of killer cell inhibitory receptors (KIRs) that specifically recognize major histocompatibility complex-class I molecules on target cells. The cytoplasmic tail of KIRs contain consensus Tyr-containing domains, which, when phosphorylated, bind to SHP-1. The interaction between the SH2 domains of SHP-1 and the phosphotyrosines of KIRs activates the phosphatase, which in turn inhibits the NK cell activation pathway. In this system, SHP-1 seems to play a negative regulatory role in antigen receptor signaling (Binstadt et al., 1997). A similar negative role has been proposed for SHP-1 in erythropoietin function. Binding of erythropoietin results in Tyr phosphorylation of its receptor and activation of the JAK2 kinase. The phosphorylated erythropoietin receptor recruits the SHP-1 phosphatase by binding via its $\mathrm{SH} 2$ domain, which in turn dephosphorylates JAK2 and terminates the erythropoietin-induced proliferation signal (Renard et al., 1997). P84 may function in a similar manner in the brain by recruitment of cytoplasmic phosphatases to juxtamembrane sites, resulting in the dephosphorylation of other proteins (activated receptors, for example), thus modulating (either positively or negatively) signaling through tyrosine kinases.
Thus, P84 may serve as a membrane-localizing protein for cytoplasmic SH2-containing proteins (phosphatases), and its function in turn may be determined by phosphorylation of the cytoplasmic Tyr residues. Critical issues that remain to be addressed include the identity of the extracellular ligand that binds P84, whether binding of this ligand results in phosphorylation of P84, the kinase that phosphorylates P84, and its precise role in the signaling pathway during synaptogenesis.

\section{REFERENCES}

Abosch A, Lagenaur C (1993) Sensitivity of neurite outgrowth to microfilament disruption varies with adhesion molecule substrate. J Neurobiol 24:344-355.

Altschul SF, Gish W, Miller W, Myers EW, Lipman DJ (1990) Basic local alignment search tool. J Mol Biol 215:403-410.

Apte AN, Siebert PD (1993) Anchor-ligated cDNA libraries: a technique for generating a cDNA library for the immediate cloning of $5^{\prime}$ ends of mRNAs. Biotechniques 15:890-893.

Ashley Jr CT, Warren ST (1995) Trinucleotide repeat expansion and human disease. Annu Rev Genet 29:703-728.

Beattie J (1996) SH2 domain protein interaction and possibilities for pharmacological intervention. Cell Signal 8:75-86.

Binstadt BA, Brumbaugh KM, Leibson PJ (1997) Signal transduction by human NK cell MHC-recognizing receptors. Immunol Rev 155:197-203.

Chuang W, Lagenaur CF (1990) Central nervous system antigen P84 can serve as a substrate for neurite outgrowth. Dev Biol 137:219-232.

Culotti JG, Kolodkin AL (1996) Functions of netrins and semaphorins in axon guidance. Curr Opin Neurobiol 6:81-88.

Dumas JB, Edwards M, Delort J, Mallet J (1991) Oligodeoxyribonucleotide ligation to single-stranded cDNAs: a new tool for cloning of 5' ends of mRNAs and for constructing cDNA libraries by in vitro amplification. Nucleic Acids Res 19:5227-5232.

Eckert C, Olinsky S, Cummins J, Stephan D, Narayanan V (1997) Mapping of the human P84 gene to the subtelomeric region of chromosome 20p. Somat Cell Mol Genet, in press.

Fannon AM, Colman DR (1996) A model for central synaptic junctional complex formation based on the differential adhesive specificities of the cadherins. Neuron 17:423-434.

Fields DR, Itoh K (1996) Neural cell adhesion molecules in activitydependent development and synaptic plasticity. Trends Neurosci 19:473-480.

Fujioka Y, Matozaki T, Noguchi T, Iwamatsu A, Yamao T, Takahashi N, Tsuda M, Takada T, Kasuga M (1996) A novel membrane glycoprotein, SHPS-1, that binds the SH2-domain-containing protein tyrosine phosphatase SHP-2 in response to mitogens and cell adhesion. Mol Cell Biol 16:6887-6899.

Goodman CS (1996) Mechanisms and molecules that control growth cone guidance. Annu Rev Neurosci 19:341-377.

Herrin DL, Schmidt GW (1988) Rapid, reversible staining of Northern blots prior to hybridization. Biotechniques 6:196-200.

Kharitonenkov A, Schnekenburger J, Chen Z, Knyazev P, Ali S, Zwick E, White M, Ullrich A (1995) Adapter function of protein-tyrosine phosphatase 1D in insulin receptor/insulin receptor substrate-1 interaction. J Biol Chem 270:29189-29193.

Kharitonenkov A, Chen Z, Sures I, Wang H, Schilling J, Ullrich A (1997) A family of proteins that inhibit signaling through tyrosine kinase receptors. Nature 386:181-186.

Margolis RL, Breschel TS, Li S-H, Kidwai AS, Antonarakis SE, McInnis MG, Ross CA (1995) Characterization of cDNA clones containing CCA trinucleotide repeats derived from human brain. Somat Cell Mol Genet 21:279-284.

Mendel-Hartwig I (1982) A simple and rapid method for the isolation of peptides from sodium dodecyl sulfate-containing polyacrylamide gels. Anal Biochem 121:215-217.

Ohnishi H, Kubota M, Ohtake A, Sato K, Sano S-I (1996) Activation of protein-tyrosine phosphatase SH-PTP2 by a tyrosine-based activation motif of a novel brain molecule. J Biol Chem 271:25569-25574.

Palay SL, Chan-Palay V (1974) Cerebellar cortex. Berlin: Springer.

Renard V, Cambiaggi A, Vely F, Blery M, Olcese L, Olivero S, Bouchet 
M, Vivier E (1997) Transduction of cytotoxic signals in natural killer cells: a general model of fine tuning between activatory and inhibitory pathways in lymphocytes. Immunol Rev 155:205-221.

Schaeren-Wiemers N, Gerfin-Moser A (1993) A single protocol to detect transcripts of various types and expression levels in neural tissue and cultured cells: in situ hybridization using digoxigenin-labeled cRNA probes. Histochemistry 100:431-440.

Singer SJ, Tokuyasu KT, Dutton AH, Chen WT (1982) High-resolution immunoelectron microscopy of cell and tissue ultrastructure. In: Electron microscopy in biology, Vol 2 (Griffith JD, ed), pp 55-106. New York: Wiley.

Sun XJ, Rothenberg P, Kahn CR, Backer JM, Araki E, Wilden PA, Cahill DA, Goldstein BJ, White MF (1991) Structure of the insulin receptor substrate IRS-1 defines a unique signal transduction protein. Nature 352:73-77.

Timchenko LT, Caskey CT (1996) Trinucleotide repeat disorders in humans: discussions of mechanisms and medical issues. FASEB J 10:1589-1597.

Wood WI, Gitschier J, Lasky LA, Lawn RM (1985) Base compositionindependent hybridization in tetramethylammonium chloride: a method for oligonucleotide screening of highly complex gene libraries. Proc Natl Acad Sci USA 82:1585-1588.

Yamao T, Matozaki T, Amano K, Matsuda Y, Takahashi N, Ochi F, Fujioka Y, Kasuga M (1997) Mouse and human SHPS-1: molecular cloning of cDNAs and chromosomal localization of genes. Biochem Biophys Res Commun 231:61-67. 